\title{
“LOOKING BACK, I WOULDN'T JOIN UP AGAIN": The Lived Experiences of Police Officers as Victims of Bias and Prejudice Perpetrated by Fellow Staff within an English Police Force
}

\section{Dr Irene Zempi}

Department of Sociology, School of Social Sciences, Nottingham Trent University, Nottignham, UK

\begin{abstract}
Women, ethnic minority and LGB police officers often experience prejudice, disadvantage and exclusion within police forces because of their perceived 'otherness' in a predominantly white, heterosexual, male organisation. In the context of an increasingly diverse service, the paper argues that the concept of intersectionality is important in order to understand the experiences of police officers who encounter bias and prejudice because of their multiple, intersecting identities. Drawing on data from qualitative interviews with 20 individuals based in an English police force, the paper examines their occupational experiences of bias, discrimination and exclusion perpetrated by their colleagues and supervisors. Utilising Hirschman's (1970) 'exit, voice and loyalty' model, the paper analyses how police officers are affected by, and respond to these experiences. Taken together, these arguments lay the foundation for future work to further understand the experiences of police officers as victims of bias and prejudice due to their multiple, intersecting identities.
\end{abstract}

Keywords: Bias; Intersectionality; Policing; Prejudice

\section{Introduction}

Traditional police recruitment patterns have overwhelmingly enlisted white, heterosexual, male officers. Both Scarman (1981) and Macpherson (1999) highlighted the failure of the police to accommodate and reflect social difference due to the restrictions of their monolithic and antiquated practices (Smith et al., 2015). Although these reviews were mainly concerned with the relationship between the police and Black Minority Ethnic (BME) communities, they led to the scrutiny of police diversity practices more broadly (McLaughlin, 2007). Specifically, the concept of 'institutional racism' became a potent mobilising concept in police reform in the United Kingdom (UK) following the publication of the Macpherson Inquiry (1999). The Inquiry's conclusion that institutional racism not only contributed to the failure of the police investigation of the racist murder of Stephen Lawrence but 'exists both in the Metropolitan Police Service and in other Police Services and other institutions countrywide' (Macpherson, 1999, 6.39) has been described as a 'watershed in race relations' (Bourne, 2001, p. 8). Correspondingly, changes to police practices were instigated by the Inquiry's extensive and wide ranging set of 70 
recommendations, together representing 'the most extensive programme of reform in the history of the relationship between the police and ethnic minority communities' (Bowling \& Phillips, 2002, p. 16). An allied development is the recruitment of individuals from minority groups and to this end, the changing face of police personnel.

However, empirical research into the occupational experiences of women, ethnic minority and LGB officers shows that they are often perceived as 'other' in a predominantly white, heterosexual, male organisation (see, for example, Bullock, 2015; Holdaway, 2015; Jones, 2015; Miller et al., 2003; O'Neill, 2015; Rowe \& Ross, 2015; Silvestri, 2015). In this regard, police officers might experience bias and prejudice within the police because of core aspects of their identity such as religion, gender, age, disability and sexual orientation, and the intersectionality amongst these aspects of identity. Yet in the aftermath of the Macpherson Inquiry and the urgency of police responses, these experiences have not been a focus of attention; instead, there has been an intense focus on race thereby ignoring - and thus sustaining - other forms of exclusion within the police (Souhami, 2014).

Drawing on data from qualitative interviews with 20 individuals based in an English police force, the aim of this paper is to throw fresh light on the lived experiences of police officers in a hypermasculine subculture and occupation. In light of an increasingly diverse police service, it is crucial to examine the occupational experiences of officers who experience bias and prejudice because of their multiple, intersecting identities, rather than examining these identities in isolation. In doing so, the paper employs the concept of intersectionality in order to understand officers' experiences of bias, prejudice and exclusion within the police because of their multiple, intersecting personal identities. Moreover the paper analyses, utilising Hirschman's (1970) 'exit, voice and loyalty' model, how police officers are affected by, and respond to these experiences. Taken together, these arguments lay the foundation for future work to further understand the experiences of police officers as victims of bias and prejudice within the police due to their multiple, intersecting identities. To this end, the study is suitable for influencing police officers' understanding of their own occupational culture, thereby contributing to changing police culture, especially through police education.

\section{Literature Review}

\section{Police Culture}

As Heslop (2011) points out, the police possess a distinctive occupational culture. Police culture refers to 'a set of shared informal norms, beliefs and values that underpins and informs police outlooks and behaviour towards people' (Loftus, 2008, p. 757). According to Heslop (2011), although the 
notion of a homogenous culture should be rejected, there are some widely shared characteristics of police culture, namely, a common subscription to mission, macho, cynicism, authoritarian conservatism, social isolation and defensive solidarity, racism, sexism, and an us/them' division of the social world (Loftus, 2010; Waddington, 1999).

Gendered police roles and attitudes are bound up with embodied power, patriarchy, and machismo (Westmarland, 2017). In her police ethnographic work, Souhami (2014) found that women staff were subject to overtly exclusionary language that was not censured by their managers. Research also shows that a masculine ethos dominates police identity (Heidensohn, 1992). According to Prokos and Padavic (2002), 'hegemonic masculinity' is a central defining concept in police culture. This can take different forms but it is generally defined through subordination of women, heterosexism, uncontrollable sexuality, authority, control, competitive individualism, aggressiveness, and capacity for violence (Fielding, 1994). Hegemonic masculinity is closely associated with 'emphasised femininity', which is based on heterosexual receptivity to men, dependence and motherhood, and is most readily associated with middle- and upper-class white women in western societies (Miller et al., 2003). In this regard, predominant images of gender implicitly include other social dimensions such as race, ethnicity, class, sexuality, and physical dis/ability, to name a few (Miller et al., 2003).

However, women are not the only group used to construct masculinity in the police. The culture of masculinity has traditionally excluded some male officers, particularly those who do not fit the requirements of hegemonic masculinity (Acker, 1990, 2006). Policing 'is defined culturally as an activity only "masculine men" can accomplish' (Messerschmidt, 1993, p. 175). This masculinity depends on the devaluation of all femininities as well as subordinated masculinities, including 'gay masculinities' (Connell, 1992; Miller et al., 2003). Burke (1994) found that the majority of LGB officers intentionally disguised their sexual orientation through a strict and premeditated performance of heterosexuality at work throughout their careers. Along similar lines, Souhami (2014) reported that some LGB staff concealed their sexuality to prevent leaving themselves 'vulnerable to abuse'. Smith et al. (2015) found that LGB officers who were not out (i.e. through not disclosing an LGB identity at work) felt immune from homophobia in the police. Yet, the psychological costs of a 'false front' are extraordinarily high in a job that is already very stressful (Goffman, 1963; Powers, 1996; Miller et al., 2003). Although a common path, this practice can bring with it serious cautionary risks namely damage to mental health and stability, an inability to give maximum attention to police duties, difficulties in forming professional relationships and high levels of withdrawal from the force before pensionable age due to psychological breakdown (Smith et al., 2015). 
Institutional Racism

The Macpherson Inquiry (1999) reported that failure to properly investigate the racist murder of Stephen Lawrence was a consequence of institutional racism. Although this Inquiry was concerned with London's Metropolitan Police Service, Macpherson's analysis of police racism was significant for constabularies throughout England and Wales. For the first time there was an acknowledgement of institutional racism across the police service. Reflecting the extent to which the term had captured the public imagination, individual officers and police services more generally found themselves under acute and negative scrutiny, both by the media and in their daily interactions with the public (Foster et al., 2005). Media exposés of highly questionable police conduct (namely, TV documentaries such as The Secret Policeman and Undercover Copper) propelled problems of police racism and sexism into public consciousness (Loftus, 2010). The Macpherson Inquiry (1999) defined 'racism' and 'institutional racism' respectively, as follows:

'Racism' in general terms consists of conduct or words or practices which advantage or disadvantage people because of their colour, culture or ethnic origin. In its more subtle form it is as damaging as in its overt form (6.4).

'Institutional Racism' consists of the collective failure of an organisation to provide an appropriate and professional service to people because of their colour, culture or ethnic origin. It can be seen or detected in processes, attitudes and behaviour which amount to discrimination through unwitting prejudice, ignorance, thoughtlessness, and racist stereotyping which disadvantage minority ethnic people (6.34).

The limitations of Macpherson's definition have been discussed in detail (see, for example, Holdaway \& O'Neill, 2006; Lea, 2003; Miles \& Brown, 2003; Solomos, 1999; Souhami, 2007, 2014; Singh, 2000; Wight, 2003). A further exploration of these shortcomings is outside the scope of this article, but one aspect is particularly relevant: the fact that institutional racism reduces experiences of discrimination and exclusion within the police to a single category (Souhami, 2014). As such, institutional racism promotes reductive explorations of single dimensions of experience. The implication of this argument is that the concept of institutional racism fails to include the experiences of bias and prejudice of all police officers; rather, it privileges certain groups and ignores other forms of exclusion such as sexism, homophobia and disablism. This paper argues that the concept of intersectionality is more appropriate to understand police officers' experiences of bias and prejudice within the police. 
Intersectionality

Intersectionality is a sociological theory that asserts that social identities are not merely independent or additive; rather multiple social identities converge to create unique experiences of oppression (Hill Collins, 1990; Crenshaw, 1989). American critical race scholar Kimberlé Crenshaw $(1989,1991)$ coined the term 'intersectionality' as a way of conceptualising identity, particularly in terms of underscoring the multidimensionality of marginalised individuals' lived experiences. Crenshaw (1989) used the metaphor of intersecting roads to describe and explain the ways in which racial and gender discrimination intersect. Specifically, Crenshaw (1989, p. 149) used the following analogy to concretise the concept:

Consider an analogy to traffic in an intersection, coming and going in all four directions. Discrimination, like traffic through an intersection, may flow in one direction, and it may flow in another. If an accident happens in an intersection, it can be caused by cars traveling from any number of directions and, sometimes, from all of them. Similarly, if a Black woman is harmed because she is in an intersection, her injury could result from sex discrimination or race discrimination ... But it is not always easy to reconstruct an accident: Sometimes the skid marks and the injuries simply indicate that they occurred simultaneously, frustrating efforts to determine which driver caused the harm.

In her work on discrimination against Black women, Crenshaw (1989) argues that they are discriminated against in ways that often do not fit neatly within the legal categories of either 'racism' or 'sexism' - but as a combination of both racism and sexism. As such, intersectionality rejects the single-axis framework (which maintains a focus on either race or gender) on the basis that this approach fails to consider how Black women are vulnerable to both grounds of discrimination. Rather, intersectionality analyses "the various ways in which race and gender interact to shape the multiple dimensions of Black women's experiences" (Crenshaw, 1991, p. 1244). The road metaphor quoted above describes the way in which a minority group "navigates a main crossing, whereby the racism road crosses with the streets of colonialism and patriarchy, and "crashes" occur at the intersections. Where the roads intersect, there is a double, triple, multiple, and many-layered blanket of oppression" (Dhamoon, 2011, p. 231).

McCall (2005, p. 1771) stresses that intersectionality has become the 'gold standard' multidisciplinary approach for analysing participants' experiences of identity and oppression, calling it 'the most important theoretical contribution 
that women's studies, in conjunction with related fields, has made so far'. Indeed, Crenshaw's formulation of intersectionality has been enormously significant, as it further opened up a conceptual space through which to identify how various oppressions work together to produce something unique and distinct from any one form of discrimination standing alone (Dhamoon, 2011). For Hancock (2007), intersectionality is not simply a normativetheoretical argument but also a research paradigm. Rather than limiting intersectionality research to 'a content specialization in populations with intersecting marginalized identities' (Hancock 2007, p. 64), this analytic paradigm can be widely applied to the study of social groups, relations, and contexts, in order to go beyond the conventional scope of non-white women (Dhamoon, 2011). In the context of the present study, intersectionality can be understood as a nexus of identities that work together to render police officers as 'other' and different due to their multiple identities, at least in the eyes of their abusers. Although there is a rising popularity of intersectionality theory, its application in the field of policing studies has been scarce and this paper aims to address this omission. As a framework of analysis that is widely applicable to various relations of marginality and privilege, intersectionality can be integrated into the field of policing studies as way of conducting research and building knowledge (Dhamoon, 2011).

Hirschman's 'exit, voice and loyalty' (EVL) model Hirschman's (1970) Exit, Voice, Loyalty (EVL) model remains one of the most influential frameworks for identifying and understanding employee behaviours and responses to organisational decline. The model has been employed across an array of schools of thought such as politics (Ross, 1988), health sciences (Dowding \& John, 2011), psychology (Burris, Detert \& Chiaburu, 2008) and criminal justice system (Mawby \& Worrall, 2013; Robinson et al., 2015). Hirschman's model consists of three elements: exit, voice and loyalty.

\section{Exit}

Exit is defined as the decision to leave an organisation as a result of declining conditions. However, Hirschman (1970) suggests that the exit function does not benefit an organisation as it fails to provide the 'feedback mechanism' for management that the voice function does. In other words, he argues that the exit mechanism does not work as a communication tool and thus it inhibits an organisation's capacity to receive feedback (Hirschman, 1970). As an alternative, the model posits the voice function as a compensatory tool for management.

\section{Voice}

Voice is the second concept described in Hirschman's model. Voice is defined as the decision taken by organisational members to communicate their concerns to the management through either formal or informal methods 
(Gehlbach, 2006). Certainly, there are situations where voice can function 'alongside or instead of the exit option' (Hirschman, 1970, p. 30). Voice is described as an 'articulation' stemming from an organisational member's desire to 'attempt to change management practices, policies and outputs of the organisation it belongs to' (Hirschman, 1970, p. 30). Therefore, voice is conceptually distinct from exit as it is an 'attempt to change rather than escape from an objectionable state of affairs' (Hirschman, 1970, p. 30). Voice can function as a tool to postpone or delay exit (Gleeson, 2016). In some cases, an organisational member is not 'ready to desert the firm but they are experiencing certain levels of unhappiness' (Hirschman, 1970, p. 34). From a managerial perspective, this should be a more desirable option because exit is an unreliable feedback mechanism for organisations attempting to reverse decline (Gleeson, 2016). Voice, in this context, should be desirable to management on the basis that, unlike exit, it gives management time to reverse the declining circumstances (Hirschman, 1970).

\section{Loyalty}

Loyalty is the final dimension of the model. Loyalty is defined as a 'special attachment' because the degree to which a member experiences it will ultimately change the conditions as to whether exit or voice is chosen (Hirschman, 1970). In some cases, voice will be chosen instead of exit, because of the individual's loyalty to the organisation, even though exit would appear to be the more logical or preferable option (Gleeson, 2016). Furthermore, Hirschman argues that a member is loyal because they either want to create a change in their organisational circumstances and to this end, stop the decline or because they remain passively loyal to their organisation and thus they will stay with 'the hope that things will get better' (Hirschman, 1970, p. 77). The model posits that loyalty 'holds exit at bay and activates voice' (Hirschman, 1970, p. 78).

Hirschman's EVL model remains one of the most seminal frameworks for scholars seeking to understand employee responses to dissatisfaction in the workplace (Gleeson, 2016). At its core, the EVL model is a framework for understanding the options available to members when responding to organisational decline and the feedback processes in response to decline made available to management, rendering it a powerful communication tool for organisations (Gleeson, 2016). Thus, it is useful to utilise this model in order to identity how police officers are affected by, and respond to their experiences of bias, discrimination and exclusion perpetrated by their colleagues and supervisors.

\section{Methodology}

This paper derives from a qualitative study, which set out to record the experiences of police officers as victims of bias and prejudice in one provincial 
police force. Potential participants were recruited by a message on the force intranet inviting police officers, staff and designated officers (e.g. PCSOs) who had experienced bias and prejudice internally to contact the author to arrange an interview. Participation in the study was voluntary. The study comprised individual, semi-structured interviews with 19 police officers and one PCSO, allowing for the collection of 'rich' data with detailed descriptions of participants' occupational experiences (Hennink et al., 2011). The sample was diverse in terms of age (from mid-20's to mid-50's), gender, ethnicity, sexuality, religion, rank, role, and length of service (from less than five years to more than 20).

This qualitative approach is especially valuable for researching sensitive issues that require confidentiality and a more intimate setting for data collection, and this is particularly appropriate for hard to access groups such as police officers who have experienced bias and prejudice internally in the police. This approach was also essential for using intersectionality for analysing participants' experiences. Intersectionality operationalises interpretivism rather than positivism, which attempts to reduce people to one category at a time (Dhamoon, 2011). While positivist methods such as statistical data analysis can provide some insights about intersectionality, these are less consistent with intersectionality because they are based on studying static, categorical variables rather than fluid and changeable forms and degrees of difference (Dhamoon, 2011; Hawkesworth, 2006).

The main aims of the research were to: (a) identify the nature of bias and prejudice directed towards police officers by fellow staff, (b) explore the impacts of these experiences and (c) determine officers' coping mechanisms and responses. The interview guide contained a series of open-ended questions related to these research questions. Interviews ranged from one to two hours, with an average interview length of one hour. Interviews were conducted face to face and they took place at the police force or at the University where the author was working at the time of the fieldwork. With the exception of one police officer (who refused to be recorded for fear of being identified), all interviews were digitally recorded, transcribed verbatim and analysed thematically. The data was reviewed and coded in order to produce categories consistent with Thematic Analysis (Braun \& Clarke, 2006). In the data analysis, quotations are presented with the participant's gender, race, and any other relevant characteristic.

It is important to briefly reflect upon the ethical assessments of the research, for example, the access to interview police officers in vulnerable situations. The 'outsider' status of the researcher (as an academic researcher not related to the police) was key to accessing participants. They argued that they were unlikely to report these experiences internally for fear of 'getting into trouble 
for speaking up'. Taking part in this study was an opportunity for participants to expose the problem of internal bias and prejudice in the police, whilst remaining anonymous. Participants argued that sharing their experiences with the researcher was 'cathartic' and empowering; they also felt 'that someone actually cared'. This indicates that this study contributed to participants' sense of confidence and enhanced their notions of being valued by listening to disclosures of bias and prejudice.

On the other hand, the research did not speak to perpetrators. Although this aspect was deliberately excluded from the parameters of this study, it is evident that it is not possible to identify the motivations that drove the perpetrators to commit the acts that they did. Rather, we have to rely on victims' testimony in order to draw conclusions about offenders' motivations. This limitation does not undermine the significance of the study but it is clear that future research should explore it in more depth.

\section{Results}

Participants reported feeling targeted because of the intersectionality of their personal identities. They described incidents of sexism, racism, homophobia as well as discrimination and hostility because of their religion, culture, disability, age and/or physical appearance. Participants also reported the operation of 'double standards' in employment areas such as probation, training, deployment and progression, as well as in the areas of complaints and misconduct investigations. These experiences had negative implications for participants' emotional, psychological and physical well-being.

\section{Experiences of bias and prejudice}

Female participants in this study described an atmosphere of all-consuming sexism and misogyny. They often felt targeted because of the intersectionality of their identities, particularly in relation to their gender, race, age and physical appearance.

He [my supervisor] used to say to me 'come on, you've got to understand that you are an individual of a minority in a majority'. I felt quite left out, he'd single me out from the rest of the officers, including the other white female officers on my shift. (Female, 48, Asian British)

My sergeant used to make jokes about my age. He would say 'you are the oldest', reference to age was a big thing for him. Reference to me being small, height was the butt of his joke all the time, other officers around the sergeant laughed, no one challenged him. This was an everyday thing. He was so 
inappropriate it was untrue. He hindered my promotion big time. (Female, 50, Asian British)

Because I'm female and young, he [sergeant] talks to me in a patronising way. Once I asked him a question and he was being sarcastic and cocky, and laughed with another senior officer. (Female, 26, Asian British)

Burke (1994) examined the occupational experiences of LGB police officers in England and Wales. His findings evidenced widespread hostility toward LGB police officers in nine forces across England and Wales. Examples included being subjected to derogatory discourse, professional humiliation, physical violence and the refusal of some heterosexual officers to work in close proximity with LGB officers. Despite the passing of over two decades, lesbian and gay officers in the present study reported similar experiences, as demonstrated in the quotes below.

Personally, I have been targeted for being gay. Before I came out, a colleague saw me in a pub having a meal with my partner, and it was two guys sat in a pub having a meal, nothing more than that. He came to the conclusion that I was gay, refused to work with me on late shifts or night shifts because he did not feel safe being a car with me. He feared I would rape him. (Male, 42, White British, gay)

This participant also felt that lesbian officers appeared to be more 'accepted' in the police in comparison to effeminate gay officers, thereby indicating the intersection of sexual orientation, gender performance and hegemonic masculinity with respect to police officers' experiences of bias and prejudice in the police.

I know of cases of lesbian policewomen who had property damaged by colleagues. But lesbian policewomen are seen as 'one of lads', other officers think 'she is good because she gets stuck in'. (Male, 42, White British, gay)

Police culture typically embraces symbols of aggressive masculinity, such as toughness and physical strength whilst excluding individuals with learning or physical disabilities who are seen as weak and inferior (Burke, 1994; Messerschmidt, 1993). Participants with learning difficulties highlighted a lack of support from their supervisors and colleagues, who failed to understand how their learning difficulty affected them. 
The organisation always promises software and coloured paper for dyslexic officers but it never materialises. (Male, 36, White British, with learning difficulties)

Supervisors don't take time to recognise or understand dyslexia. I am expected to do the same as everyone else despite my dyslexia. I don't get much support. They don't understand that my learning style is different, including the work. I am just a number for the control room. They call me on the radio, and they will give me the job, then they give me another one, and then another one. The more anxiety, the more dyslexic I get. (Male, 41, Asian British, with learning difficulties)

Another participant who was 'different' on the basis of his sexual orientation and disability, reported being fearful of the organisation finding out that he is dyslexic, as indicated in the quote below.

Hidden disabilities is a huge problem in the police. I have to work twice as hard to prove myself. Being dyslexic myself, I spend so much time doing written work, I take work home to cope. I've recently been diagnosed with dyslexia, but what ammunition does this give my boss? He can't do anything about my sexuality because I am out, they can't homophobically bully me anymore, but if my written work is poor and I give them a reason to say my work is poor, they might say 'if you can't work at this level, we must get rid of you'. (Male, 42, White British, gay, with learning difficulties)

Probation, training, deployment and progression

Participants reported the operation of double standards in employment areas including probation, training, deployment and progression; however, it was not possible to prove that they were discriminated against because of their personal identities. BME officers described how their probationary periods had been monitored more strictly, how their progression had been held back and how their supervisors had shown preferential treatment to their white colleagues. This is a typical example of how a black male officer's progression and development was blocked by his sergeant.

A CID opportunity opened, and I had to speak to my sergeant to get authorisation in terms of applying. I spoke to him and his response was 'we are not going to support you'. It was obvious that they didn't want me to apply, they wanted to keep me in uniform at the station for the next 20 odd years till I retired. (Male, 35, Black British) 
Female BME officers described both racism and sexism as creating barriers to their career progression whilst male BME officers argued that in some cases they were discriminated against because of the intersectionality between their race, religion and culture, as indicated in the quote below.

A former Assistant Chief Constable told me that I would not be promoted because I'm Asian, Muslim and because 'I don't go out with the gang' eg I don't play the game - drinking and socialising with fellow staff. (Male, 44, Asian British, Muslim)

This resonates with previous studies (Cashmore, 2001; Holdaway \& Barron 1997; Jones \& Williams, 2015; Smith et al., 2015), which reported that different standards appear to be operating for BME police staff across the areas of progression and performance management. According to Colvin (2008), high supervisory discretion in the areas of deployment and promotion is likely to partly explain higher chances of discrimination. Jollevet (2008) argues that police culture is exclusionary based on the premise that by excluding minority officers, white officers have an advantage in job assignments, promotions, and advancement. Furthermore, both male and female BME officers in this study reported being discriminated against in the areas of complaints and misconduct investigations.

If you are Black or Asian and you're driving around in an expensive car, professional standards will be investigating you. That has happened to 3-4 people that I know. It makes you think why is it that if you are BME officer and you drive a nice car you are likely to be investigated but they don't do the same for white officers? Then you find that they go through your bank accounts. (Male, 33, Asian British)

I've suffered a hard time in the police in terms of being able to get on and progress. Every time l've gone for something it's been difficult. I've had a lot of unfair criticism, and unfair reports written against me. The way I was treated in personal situations was always very harsh. In disciplinary cases I had to fight the organisation. (Male, 35, Black British)

Evidence highlights the problem in misconduct proceedings whereby BME officers are disproportionately subjected to misconduct investigations (CalvertSmith, 2005; Ghaffur, 2004; Morris, 2004; Muir, 2001; National Black Police Association, 2009). In 2010, an Association of Chief Police Officers (ACPO, 2010) survey of 40 police forces concluded that BME officers were overrepresented in internal misconduct and covert counter-corruption 
proceedings. Internal police reviews (Ghaffur, 2004) and external reviews for public bodies with responsibilities for oversight of the police (Calvert-Smith, 2005; Morris, 2004) highlight the apparent preference of supervisors to refer the behaviour of BME officers to professional standards departments for formal investigation, whereas they would deal with white officers informally face-to-face.

However, it is important to note that concerns about double standards were not reported solely by BME officers in this study. White police officers who took part in the study also felt victims of bias and prejudice because of the (perceived) need for the organisation to proactively support the progression of female, gay and/or racial minority colleagues.

If I was female or had a different colour skin I would have better chance of promotion. (Male, 36, White British, Heterosexual)

My friend submitted two applications one as 'bisexual' and one as 'heterosexual'. The former was accepted, the latter rejected. Many stories circulate of people getting on if they are diverse. (Male, 34, White British, Heterosexual)

In addition, BME officers reported being challenged by their white colleagues for having a perceived advantage in terms of progression due to their racial minority status.

I remember when the firearms were advertising on the intranet it said 'our department particularly welcomes applications from minorities because they are underrepresented in our department'. I can remember comments coming from the other desks from white cops 'I would be interested in that but I am not Black and I am not gay'. I do feel that if you are a BME you have to work harder. You get people who say that 'you only got that because you are Black'. (Male, 48, Black British)

Impacts of bias and prejudice

Bias, prejudice and discrimination in the workplace create a hostile and stressful environment that affects individuals' well-being. The adverse health effects of prejudice on the lives of affected individuals and groups are well evidenced (Allport, 1954; Goffman, 1963; Jones et al., 1984; Link \& Phelan, 2001). In this study, participants experienced a range of emotions including sadness, hurt, anger, job insecurity, isolation, mistrust, vulnerability and injustice. Some participants felt extremely depressed by their experiences, whilst others felt demotivated and had lost enthusiasm for their work due to what might be termed occupational burnout or emotional exhaustion. As the 
following quotes demonstrate, many participants reported feelings of withdrawal, with comments that they were no longer willing to 'go the extra mile' for the force.

I question whether I am in the right job. I feel demotivated, I don't look forward to work. (Male, 53, Asian British, Muslim)

Why was I treated like this whereas my white colleagues had it easy? I felt picked on and it was for nothing. I feel demotivated, I didn't join for this. (Male, 41, Asian British, with learning difficulties)

Feelings of stress and anxiety were also common amongst participants, as indicated in the comment below.

Often in the car I feel that my partner does not want me there. He is grumpy, does not engage in conversation, you know when people don't like you, and l've seen how he is with other people. Spending nine hours in the car like that is stressful. (Male, 41, Asian British, with learning difficulties)

Many participants felt isolated and lonely in their work, implying a lack of informal and/or formal support.

I have felt variously lonely, left out, obliged to work harder. The big unanswered question for me is why do I get picked on because of my identity? (Male, 37, Asian British, with learning difficulties)

I do feel very lonely. Why am I treated differently? How it is possible that after nine years in the force I have so many examples to give where I have been treated differently? (Male, 35, Black British)

Feelings of loneliness and isolation were exacerbated by the fact that some participants did not feel it was appropriate to share their experiences with their co-workers.

People will say I'm playing the race card. Being a victim and speaking up, not everyone will be supportive. People talk and gossip and then it creates a bit of a sentiment, can this person be trusted to make comments around them or shall we just be quiet when that person is around? (Male, 29, Asian British, Sikh) 
I can't rely on my colleagues. I've learnt that early on in my career. My confidence in the organisation has gone. I am very cautious, I write everything down. Internal racism makes you very wary. (Female, 48, Asian British)

As might be expected, experiences of bias and prejudice had negative implications for participants' emotional, psychological and physical well-being.

It [racism and sexism] has affected me mentally. I have been on anti-depressants. (Female, 48, Asian British)

People keep quiet - no supervisory support as it goes against cultural norms - and go sick, abuse is the root cause and the force doesn't know. (Male, 36, White British, with learning difficulties)

Officers' mental health will be affected, their physical health will be affected, but we will attribute that to something else. It could be that people turn to food, so their weight becomes a problem but we never address the reasons why they got on weight, or people turn to alcohol, but we don't ask 'why are you drinking?' (Male, 42, White British, gay)

Finally, some of our participants adopted a defensive, guarded persona through which they protected their personal identities by keeping their privacy, such as living a double-life for gay police officers.

Before I came out, I almost had two lives, two different worlds and the two would never meet. Living in secrecy can have a damaging impact. It was very tiring emotionally. I know colleagues who gave their same sex partner, opposite's gender name in conversations with other people to make it easier for them. (Male, 42, White British, gay)

Responses to bias and prejudice

In analysing participants' responses to their experiences of bias and prejudice within the police, this paper draws on Hirschman's (1970) 'exit, voice and loyalty' (EVL) model which has been used to map and compare employees' responses to adverse working conditions, including in the criminal justice context (Mawby \& Worrall, 2013; Robinson et al., 2015).

Exit

The category of exit involves physically or psychologically leaving the organisation. This includes the responses of withdrawing enthusiasm, going 
on sick leave, taking a career break, thinking about leaving or actually leaving for good. Cooper and Ingram (2004) researched police retention and found that there was a higher rate of resignations of BME officers compared to all officers, a situation which remains (Home Affairs Committee, 2016). Participants reported similar responses, as illustrated in the comments below.

I feel so sorry for young Black and Asian officers [says this several times during interview]. Looking back, I wouldn't join up again. (Male, 53, Asian British, Muslim)

Statistics show that in England and Wales Black officers are less likely to serve a full career in the police than their white counterparts. You have to ask yourself why is that? Why are black cops quitting the force? Maybe they feel they don't fit in, they don't belong or they had experiences like me and thought why should I put up with this rubbish? I'm getting out of this. (Male, 48, Black British)

For some officers, the exit was psychological rather than actual, as the following comments demonstrate.

Sometimes I think I will come to work, I will do the bare minimum and I'm going home, that's it. (Male, 35, Black British)

The police have taken away my enthusiasm, they have taken away my commitment, they have taken away my fight for it. I am a real fighter, but I'm thinking 'it is not worth fighting anymore, I don't want it anymore'. (Female, 50, Asian British)

Voice

The category of voice is a response whereby employees speak up, expressing their concerns and dissatisfaction to management and others, in some cases through involvement with a staff association or working group. This includes the responses of working from within and being honest about the issues, recording, challenging and fighting injustices, and actively supporting minority groups though official support networks in the police. In some cases, participants felt inclined to make a formal complaint in order to register their objection to their colleagues' behaviour. However, when participants did make a formal complaint against their colleagues, they perceived that their case was not correctly recognised, understood or addressed in internal investigations and/or tribunals. In some cases, they were threatened by their supervisors that they had to resign. This meant that participants felt 'doubly victimised'. 
My sergeant told me I had to resign if I were to go to the tribunal [regarding cases of racism and sexism] but I told him 'why should I resign? I have not done anything wrong'. (Female, 48, Asian British)

Some participants reported feeling 'betrayed' by their colleagues who failed to support them in tribunal cases after they had activated the voice response.

Following incidents of racism by supervisor, I began documenting everything and submitted formal complaint. Went to tribunal and read the papers which suggested that the supervisor was openly dismissive of Asian officers and had fixed negative attitudes. Senior officers had memory loss at tribunal -1 felt betrayed. (Male, 53, Asian British, Muslim)

My sergeant said that my colleagues find me unapproachable and that they are not comfortable working with me but it wasn't true. I asked my colleagues and they said they were happy to work with me but when it came to giving statements from my colleagues [at the tribunal for case of gender and race discrimination], they supported the sergeant rather than me. It did disturb me. I was off work for six months on stress. That's when I faced the reality of racism in the force. I felt betrayed by my colleagues because we used to work together, laugh together and then they took his side. (Female, 48, Asian British)

Other participants reported being subjected to greater scrutiny by their supervisors after speaking up, and had higher chances of being subjected to misconduct proceedings, which served as an effective deterrent to taking the voice option in the future. In these cases, participants were seen as rebels who openly questioned the authority of their abusers. The use of misconduct proceedings also served to disrupt the career development of officers who had previously spoken up. Participants argued that they were encouraged to report behaviour of fellow staff they considered to be biased or prejudiced, only to discover that they would then be investigated for misconduct.

I am afraid that if a complaint comes for me, they will do my legs, it is like 'we will get you'. That is a real threat to me. I have upset a lot of people by refusing to be bullied. (Female, 50, Asian British)

Loyalty

The third component of Hirschman's model is loyalty. Representing the position of employees who feel an attachment to the organisation and who 
commit to staying with the organisation waiting, mainly but not always passively, for better times. This is a complex option for victims of discrimination operating within the prevalent police culture. An occupational rule, albeit unwritten, was that participants were expected to abide by the code of silence masked as loyalty to the police family. In this regard, they were expected not to voice their experiences of bias and prejudice in order to demonstrate solidarity with their colleagues. As Heslop (2011) points out, solidarity with colleagues is one of the defining features of police culture. In her ethnography, Loftus (2010) found that group loyalty was robust between officers on the same shift, and was no doubt encouraged by the predominantly white, heterosexual, male composition of such shifts. In organisational terms, solidarity is a favourable trait as it produces a high degree of team work, but it also has a sinister face insofar as it encourages the protection and covering up of colleague infringements of procedure (Loftus, 2010).

Correspondingly, some participants in this study reported being reluctant to take the voice option for fear of the repercussions; this placed them in a loyalty by default position. This was because of fears about being left out of the group and/or apprehensions about one's career prospects if they spoke up. Some participants feared retribution and stated that they would be marked as troublemakers if they reported their experiences of bias and prejudice to their supervisors. However, as evidenced earlier, other participants were prepared to exercise their voices and this can meld with Hirschman's notion of loyalty as a characteristic of employees who feel an attachment to the organisation, which acts as a psychological barrier to exit. This includes officers from minority groups who accept that they have to work harder to achieve equal treatment to majority group colleagues. It also includes those who believe they have to stay in the force if things are to change.

Asians that approach me in the street ask if the police are racist. They are, but you've got to be in it to make a difference. (Male, 44, Asian British)

Every day it chips away at you. In 1990 I left, worn down by it all. I was treated differently due to my skin colour. I returned to fight my corner. (Male, 52, Black British)

\section{Discussion}

In the post-Macpherson era of policing there has been a gradual rise in the recruitment of individuals from minority ethnic, female, and gay and lesbian groups. However, they remain vastly outnumbered by their white, heterosexual, male counterparts. Minority officers might be seen as 'outsiders' in the police world whereby the 'in-group' is overwhelmingly white, 
heterosexual and male. Police culture is often cited as the source and justification for bigoted and prejudiced attitudes and behaviours (Reiner, 2010). Minority officers may support new styles of policing and thus dilute the established police culture (Foster, 2003). Canteen culture, the informal talk among police staff away from public view, prioritises discriminatory banter including sexism, homophobia and racism (Waddington, 1999). Gamson (1997) states that the process of a collective identity requires 'difference'. To this end, minority officers become tools in the construction of boundaries that define the geography of 'belonging' and delineate who is 'in' and who is 'out' (Marti, 2001).

Correspondingly, participants in the present study reported being targeted because of their perceived 'difference'. They described incidents of sexism, racism, homophobia as well as discrimination and hostility because of their religion, culture, disability, age and/or physical appearance. To illustrate this, female participants described being targeted because of the intersectionality of their identities, particularly in relation to their gender, race, age and physical appearance. Indeed, the research literature shows that policing is traditionally gendered, sexualised, and racialised (Holdaway, 2015; Jones, 2015; Muftić \& Collins, 2014; Rowe \& Ross, 2015; Silvestri, 2015). However, it is important to recognise that female participants in this study did not experience racism because they are BME, and sexism because they are women; they experienced both simultaneously on the basis that "racism and sexism interlock, they modulate and inflect one another" (Lloyd, 2005, p. 45). Taking a similar position, Spelman (1990) states that "sexism and racism do not have different objects" (p. 12).

In this context, it is useful to consider the work of Hill Collins (1990) who refers to the structural dimension of intersectionality as a 'matrix of domination' in which gender, race, class and other 'axes of oppression' interconnect and operate together to produce diverse experiences of domination within a structured whole. Intersectionality, then, does not engage in an analysis of separate systems of oppression (such as gender, race and class) but explores how these are mutually constitutive, coupled with other aspects of identity (Boogaard \& Roggeband, 2016). This infers that there is no clear ranking of identities and that intersectionality cannot be understood using mathematical frameworks such as 'additive', 'multiplicative' or 'triple jeopardy' (Prins, 2006). Rather, 'intersecting categories result in unique experiences of inequality and opportunity that are more than the sum of their parts' (Boogaard \& Roggeband, 2016, p. 72).

Participants also reported the operation of 'double standards' in employment areas such as probation, training, deployment and progression, as well as in the areas of complaints and misconduct investigations. Utilising Hirschman's 
(1970) 'exit, voice and loyalty' model, the paper analysed how police officers were affected by, and respond to these experiences. The model asserts that members have two potential avenues when responding to organisational decline - exit or voice; they can either choose to exit the organisation or they can choose to express their concerns to management through the voice mechanism. Some participants chose the exit function and reported physically or psychologically leaving the organisation. Other participants chose to speak up, expressing their concerns and dissatisfaction to management, in some cases through involvement with a staff association or working group. Others argued that they had to stay in the force if things were to change, thereby employing the loyalty mechanism.

\section{Conclusion}

In the wake of two landmark inquiries by Scarman (1981) and Macpherson (1999), a plethora of reform initiatives placed a legal, business and ethical case for diversity and the aim for the police to reflect the diverse communities that they serve at their core (Clements, 2008; HMIC, 2003). On the face of it, the new working climate in the police is based on standards which are rhetorically free from discrimination, challenge bias and prejudice, and include paths of recourse for those who fail to achieve the desired level of professionalism (Smith et al., 2015). However, as this study has shown, despite considerable improvements in police working environments for minority officers, instances of sexism, racism, homophobia and intolerance towards difference are still evident in British policing.

Drawing on data from qualitative interviews with 20 individuals based in an English police force, the paper examined police officers' experiences of bias, discrimination and exclusion perpetrated by their colleagues and supervisors. Participants reported being targeted because of core aspects of their identity such as gender, race, religion, culture, age, disability and sexual orientation, and the intersectionality amongst these aspects of identity. The article has argued that the focus on institutional racism has created something of an analytical straitjacket and that, based on this study, intersectionality offers a promising conceptual resource to think about and examine ongoing problems of bias and discrimination at individual and organisational levels within police forces. This is important not only for the purpose of addressing internal divisions and fostering coherent effective police organisations, but also in the interest of creating a representative police service, which is suitable to meet the needs of multicultural communities, and offer services that reflect the high diversity of communities (Alpert et al., 2014). Indeed, research shows that members of minority groups have low confidence in the police (Beare, 2016; Dowler \& Sparks, 2008; Morris, 2015). In a recent study of public perceptions of a police constabulary in the UK, Awan et al. (2018) found that BME participants were less satisfied with the police, and considered they had been 
treated more unfairly, were less trusting of the police and viewed the police as less helpful than non-BME participants. Awan et al. (2018) also found that there was a fear of institutional racism and a lack of career development, and this deterred BME members of the public from considering and beginning the application process for joining the police. Both Mason et al. (2014) and Holdaway (2010) note the reluctance of minority groups as a barrier to joining the police.

Since the Macpherson Report (1999) there has been constant pressure on the police to increase the representation of police staff from minority ethnic, female, and gay and lesbian backgrounds. In May 2016, the Home Affairs Committee reiterated that 'urgent and radical action' is needed to tackle the gross under-representation of BME people in the police forces of England and Wales, which the police service has 'consistently failed to address' over several decades. The statistics on police diversity are stark and it is difficult to envisage how problems of bias and prejudice internally will be addressed while this remains the case. Indeed, with respect to the 'lessons learned' from this study, it is clear that the experiences of the participants in this study have implications for police training, organisational policies, processes, communications, support mechanisms, first line supervision as well as police leadership. These would be modest steps towards building and maintaining a diverse police service that mirrors 21st Century communities in terms of gender, age, religion, race, disability and sexuality. 


\section{References}

Acker, J. (1990). Hierarchies, Jobs, Bodies: A Theory of Gendered Organizations. Gender and Society, 4(2), 139-58.

Acker, J. (2006). Inequality Regimes: Gender, Class and Race in Organizations. Gender and Society, 20(4), 441-64.

Alpert, G.P., Dunham, R.G., \& Stroshine, M.S. (2014). Policing: continuity and change (2nd ed.). Long Grove, IL: Waveland Press.

Allport, G.W. (1954). The nature of prejudice. Reading, MA: Addison-Wesley.

Anthias, F. \& Lloyd, C. (2002). Rethinking anti-racism: from theory to practice. London: Routledge.

Anthias, F. \& Yuval-Davis, N. (1992). Racialized Boundaries: Race, Nation, Gender, Colour and Class and the Anti-racist Struggle. London: Routledge.

Association of Chief Police Officers (2010). Implementation of the New Misconduct Arrangements: Impact upon Officers from Minority Ethnic Groups. London: Association of Chief Police Officers.

Awan, I., Brookes, M., Powell, M. \& Stanwell, S. (2018). Understanding the public perception and satisfaction of a UK police constabulary. Police, Practice and Research: An International Journal, DOI:

10.1080/15614263.2018.1428098.

Beare, M. (2016). What matters in policing? Change, values, and leadership in turbulent times. Police, Practice and Research: An International Journal, 18(2), 207-209.

Boogaard, B. \& Roggeband, C. (2010). Paradoxes of intersectionality: theorizing inequality in the Dutch police force through structure and agency. Organization, 17(1), 53-75.

Bourne, J. (2001). The life and times of institutional racism. Race and Class, 43(2), 7-22.

Braun, V. \& Clarke, V. (2006). Using thematic analysis in psychology. Qualitative Research in Psychology, 3(2), 77-101. 
Burke, M. (1994). Homosexuality as Deviance: The Case of the Gay Police Officer. British Journal of Criminology, 34(2), 192-203.

Bullock, K. (2015). Diversity in the Special Constabulary Policing. A Journal of Policy and Practice, 9(1), 46-55.

Burris, E.R., Detert, J.R. \& Chiaburu, D.S. (2008). Quitting before leaving: The mediating effects of psychological attachment and detachment on voice. Journal of Applied Psychology, 93(4), 912-922.

Calvert-Smith, D. (2005). The Police Service in England and Wales: Final report of a formal investigation by the Commission for Racial Equality. London: Commission for Racial Equality.

Cashmore, E. (2001). The experiences of ethnic minority police officers in Britain: under-recruitment and racial profiling in a performance culture. Ethnic and Racial Studies, 24(4), 642-659.

Clements, P. (2008). Policing a diverse society (2nd ed.). Oxford: Oxford University Press.

Colvin, R. (2008). Shared perceptions among lesbian and gay police officers: barriers and opportunities in the law enforcement work environment. Police Quarterly, 12(1), 86-101.

Connell, R.W. (1992). Gender and power. Palo Alto, CA: Stanford University Press.

Cooper, C. \& Ingram, S. (2004). Retention of Police Officers: A study of resignations and transfers in ten forces. London: Home Office.

Crenshaw, K. (1989). Demarginalizing the Intersection of Race and Sex: A Black Feminist Critique of Antidiscrimination Doctrine. The University of Chicago Legal Forum, 139-67.

Crenshaw, K. (1991). Mapping the margins: intersectionality, identity politics, and violence against women of color. Stanford Law Review, 43(6), 12411299.

Dhamoon, R. K. (2011). Considerations on mainstreaming intersectionality. Political Research Quarterly, 64(1), 230-243.

Dowding, K. and John, P. (2011). Voice and choice in health care in England: Understanding citizen responses to dissatisfaction. Public Administration, 89(4), 1403-1418. 
Dowler, K. \& Sparks, R. (2008). Victimization, contact with police, and neighbourhood conditions: Reconsidering African American and Hispanic attitudes towards the police. Police, Practice and Research: An International Journal, 9(5), 395-415.

Fielding, N. (1994). Cop Canteen Culture. In T. Newburn \& E.A. Stanko (Eds.), Just Boys Doing Business? Men, Masculinities and Crime (pp. 46-63). London: Routledge.

Foster, J. (2003). Police Cultures. In T. Newburn (Ed.), Handbook of Policing (pp. 196-227). Cullompton: Willan.

Foster, J., Newburn, T. \& Souhami, A. (2005). Assessing the Impact of the Stephen Lawrence Inquiry, Home Office Research Study 294. London: Home Office.

Gamson, J. (1997). Messages of Exclusion: Gender, Movements, and Symbolic Boundaries. Gender and Society, 11(2), 178-99.

Gehlbach, S. (2006). A formal model of exit and voice. Rationality and Society, 18(4), 395-418.

Ghaffur, T. (2004). Thematic review of race and diversity in the metropolitan police service. London: Metropolitan Police Service.

Gleeson, E. (2016). Re-conceptualising Hirschman's Exit, Voice \& Loyalty model for contemporary organisational contexts (Master of Business (Thesis). University of Notre Dame Australia.

Goffman, E. (1963). Stigma: Notes on the management of spoiled identity. New York: Touchstone.

Hancock, A. (2007). When multiplication doesn't equal quick addition: Examining intersectionality as a research paradigm. Perspectives on Politics, 5(1): 63-79.

Hawkesworth, M. (2006). Contending conceptions of science and politics: Methodology and the constitution of the political. In D. Yanow and P. Schwartz-Shea (Eds.), Interpretation and method: Empirical research methods and the interpretative turn (pp. 27-49). Armonk, NY: M. E. Sharpe.

Heidensohn, F. (1992). Women in Control - The Role of Women in Law Enforcement. Oxford: Oxford University Press. 
Hennink, M., Hutter, I. \& Bailey, A. (2011). Qualitative Research Methods. London: Sage.

Heslop, R. (2011). Reproducing police culture in a British university: findings from an exploratory case study of police foundation degrees. Police, Practice and Research: An International Journal, 2(4), 298-312.

Hill Collins, P. (1990). Black Feminist Thought. London: Harper-Collins.

Hirschman, A. O. (1970). Exit, Voice and Loyalty: Responses to Decline in Firms, Organizations and States. Cambridge, MA: Harvard University Press.

HMIC (2003). Diversity matters. London: Home Office.

Holdaway, S. (2010). Understanding 'trust' and 'confidence': Problems within and out with constabularies. Policing: A Journal of Policy and Practice, 4(3), 258-264.

Holdaway, S. (2015). What Do We Know? Lessons from the History of Race Relations within Constabularies. Policing: A Journal of Policy and Practice, 9(1), 5-14.

Holdaway, S. \& Barron, A. (1997). Resigners? The experiences of Black and Asian police officers. London: Macmillan.

Holdaway, S. \& O'Neill, M. (2006). Institutional racism after Macpherson: an analysis of police views. Policing and Society, 16(4), 349-369.

Home Affairs Committee (2016). Police Diversity. London: House of Commons.

Jones, M. (2015) Who Forgot Lesbian, Gay and Bisexual Police Officers? Findings from a National Survey. Policing: A Journal of Policy and Practice. 9(1), 65-76.

Jones, M. \& Williams, M. (2015). Twenty years on: lesbian, gay and bisexual police officers' experiences of workplace discrimination in England and Wales. Policing and Society, 25(2), 188-211.

Jones, E.E., et al., (1984). Social stigma: The psychology of marked relationships. New York: Freeman.

Jollevet, F. (2008). African American police executive careers: Influences of 
human capital, social capital, and racial discrimination. Police, Practice and Research: An International Journal, 9(1), 17-30.

Lea, J. (2003). Institutional racism in policing: the Macpherson report and its consequences. In R. Matthews \& J. Young (Eds.), The new politics of crime and punishment (pp. 48-70), Cullompton: Willan.

Link, B. G., \& Phelan, J. C. (2001). Conceptualizing stigma. Annual Review of Sociology, 27, 363-385.

Loftus, B. (2008). Dominant culture interrupted: Recognition, resentment and the politics of change in an English Police Force. British Journal of Criminology, 48, 756-777.

Loftus, B. (2010). Police occupational culture: classic themes, altered times. Policing and Society, 20(1), 1-20.

Lloyd, M. (2005). Beyond Identity Politics: Feminism, Power and Politics. UK: Sage.

McCall, L. (2005). The complexity of intersectionality. Signs, 30(31), 17711802.

Macpherson, W. (1999). The Stephen Lawrence Inquiry. London: HMSO.

Mason, D., Hillenbrand, C., \& Money, K. (2014). Are informed citizens more trusting? Transparency of performance data and trust towards a British Police Force. Journal of Business Ethics, 122(2), 321-341.

Messerschmidt, J. (1993). Masculinities and crime: Critique and reconceptualization of theory. Lanham, MD: Rowman \& Littlefield.

Miles, R. \& Brown, M. (2003). Racism. London: Routledge.

Miller, S. L., Forest, K.B., \& Jurik, N.C. (2003). Diversity in blue: lesbian and gay police officers in a masculine occupation. Men and Masculinities, 5(4), 355-385.

Morris, C. (2015). An international study on public confidence in police. Police, Practice and Research: An International Journal, 16(5), 416-430.

Morris, W. (2004). The Case for Change: People in the Metropolitan Police Service. London: Morris Inquiry. 
Muir, R. D. (2001). The Virdi Inquiry Report. London: Metropolitan Police Authority.

Muftić, L. R. and Collins, S. C. (2014). Gender attitudes and the police in Bosnia and Herzegovina: male officers' attitudes regarding their female counterparts. Police, Practice and Research: An International Journal, 15(5), 389-403.

National Black Police Association (2009). The Post Stephen Lawrence Decade. London: National Black Police Association.

O'Neill, M. (2015) The Case for the Acceptable 'Other': The Impact of Partnerships, PCSOs, and Neighbourhood Policing on Diversity in Policing. Policing: A Journal of Policy and Practice, 9(1), 77-88.

O'Neill, M. \& Holdaway, S. (2007). Examining 'window dressing': The views of black police associations on recruitment and training. Journal of Ethnic and Migration Studies, 33(3), 483-500.

Powers, B. (1996). The impact of gay, lesbian, and bisexual workplace issues on productivity. Journal of Gay and Lesbian Social Services, 4(4), 79-90.

Prins, B. (2006). Narrative Accounts of Origins. A Blind Spot in the Intersectional Approach? European Journal of Women's Studies, 13(3), 277290.

Prokos, A., \& Padavic, I. (2002). There oughtta be a law against bitches: masculinity lessons in police academy training. Gender, Work and Organization, 9(4), 439-59.

Reiner, R. (2010). The Politics of the Police (4th ed.). Oxford: Oxford University Press.

Robinson, G., Burke, L. \& Millings, M. (2015). Criminal Justice Identities in Transition: The Case of Devolved Probation Services in England and Wales. British Journal of Criminology, 56(1), 161-178.

Ross, M. H. (1988). Political organization and political participation: Exit, voice, and loyalty in preindustrial societies. Comparative Politics, 21(1), 73-89.

Rowe, M., \& Ross, J. (2015). Comparing the Recruitment of Ethnic and Racial Minorities in Police Departments in England and Wales with the USA. Policing: A Journal of Policy and Practice, 9(1), 26-35 
Scarman, Lord Justice (1981). The Scarman report: the Brixton disorders. London: HMSO.

Silvestri, M. (2015). Gender Diversity: Two Steps Forward, One Step Back ... Policing: A Journal of Policy and Practice, 9(1), 56-64.

Singh, G. (2000). The concept and context of institutional racism. In A. Marlow \& B. Loveday (Eds.), After Macpherson: policing after the Stephen Lawrence Inquiry (pp. 29-40). Lyme Regis: Russell House.

Smith, G., Haggar Johnson, H. \& Roberts, C. (2015). Ethnic minority police officers and disproportionality in misconduct proceedings. Policing and Society, 25(6), 561-578.

Solomos, J. (1999). Social research and the Stephen Lawrence Inquiry. Sociological Research [online], 4(1). Retrieved from:

http://www.socresonline.org.uk/4/lawrence/solomos.html

Souhami, A. (2007). Transforming youth justice: occupational identity and cultural change. Cullompton: Willan.

Souhami, A. (2014). Institutional racism and police reform: an empirical Critique. Policing and Society, 24(1), 1-21.

Spelman, E. V. (1990). Inessential Woman. London: The Women's Press.

Westmarland, L. (2017). Putting their Bodies on the Line: Police Culture and Gendered Physicality. Policing: A Journal of Policy and Practice, 3(1), 301317.

Wight, C. (2003). The agent structure problem and institutional racism. Political Studies, 51(4), 706-721. 